\title{
Parceria Trans-Pacífico: Novas Geometrias no Capitalismo Global*
}

\author{
Hoyêdo Nunes Lins**
}

\section{Introdução}

Acordos comerciais entre países representam iniciativas de alguma recorrência nas relações econômicas internacionais. Diversificadas no teor e na abrangência, essas ações passaram a vincar o cenário após a Segunda Guerra Mundial, principalmente, com importantes repercussões em vários casos.

Embora a maioria das experiências possa sugerir o contrário, a vizinhança ou a proximidade geográfica entre os países envolvidos não é aspecto sempre respeitado nesses acordos. São ilustrativos os movimentos observados desde meados dos anos 2000, intensificados na

\footnotetext{
* Artigo recebido em 13 de agosto de 2013 e aprovado para publicação em 6 de junho de 2014.

** Doutor em Geografia (Organização do Espaço), pela Université de Tours (Université Francois Rabelais) e professor titular da Universidade Federal de Santa Catarina (UFSC). E-mail: hoyedo. lins@ufsc.br.
}

CONTEXTO INTERNACIONAL Rio de Janeiro, vol. 36, nº 2, julho/dezembro 2014, p. 623-653. 
presente década, para concretizar um acordo interligando países das bordas oriental e ocidental do Oceano Pacífico: a Parceria Trans-Pacífico (Trans-Pacific Partnership).

Essa parceria é o objeto deste artigo. A importância do assunto, inegável para quem estuda as relações econômicas e políticas internacionais na atualidade, transparece nos contornos, no escopo e principalmente nas acenadas implicações, inclusive em termos geopolíticos, dessa iniciativa. Diferentes abordagens, com distintos perfis e origens institucionais, convergem nesse reconhecimento.

O objetivo do artigo é duplo. Primeiramente, expor e discutir alguns elementos centrais das negociações sobre a Parceria Trans-Pacífico, assinalando as questões mais polêmicas. Em seguida, explorar aspectos de natureza geopolítica, destacando o problema da motivação, quanto ao envolvimento e à orientação imprimida, do país que assumiu a liderança do processo.

Essa sequência de objetivos marca a estrutura do texto. Após caracterizar a parceria, indicando o contexto do seu surgimento e apresentando alguns dados sobre os países implicados, adentra-se o conteúdo das negociações. Com base em vários documentos, discorre-se sobre algumas questões econômicas do acordo, mostrando o seu alcance e complexidade e sublinhando o caráter controverso de várias propostas. Depois, explora-se o ângulo geopolítico, tentando perscrutar, em reflexão estribada em pesquisa bibliográfica, aspectos da participação dos Estados Unidos.

\section{Parceria Trans-Pacífico: Do que se Trata?}

Em julho de 2005, Brunei, Chile, Cingapura e Nova Zelândia firmaram o Acordo de Parceria Econômica Estratégica Trans-Pacífico (em inglês, Trans-Pacific Strategic Economic Partnership Agree- 
ment), com o propósito de ampliar suas relações por meio da "liberalização do comércio e dos investimentos e pelo encorajamento de uma maior e mais profunda cooperação, para criar uma parceria estratégica na região Ásia-Pacífico" (TRANS-PACIFIC..., 2005, p. 1). A intenção de "fortalecer a competitividade de suas empresas nos mercados globais" (TRANS-PACIFIC..., 2005, p. 1) associava-se à de "estimular a criatividade e a inovação, e promover a proteção dos direitos de propriedade intelectual para impulsionar o comércio de bens e serviços" (TRANS-PACIFIC..., 2005, p. 1).

Tendo como marco institucional a Asia-Pacific Economic Cooperation (APEC), esse acordo recobriria a economia, mormente no tocante à agricultura e aos recursos florestais, e envolveria também pesquisa, ciência e tecnologia, além de educação e cultura. Cada país suprimiria os obstáculos ao comércio e aos investimentos entre os membros, assegurando mercados abertos e o caráter concorrencial das interações. Isso implicaria, por exemplo, a retirada de subsídios às exportações agrícolas e um tratamento nacional aos bens vindos dos demais países, algo que se estenderia ao comércio de serviços e às compras governamentais de bens e serviços.

Sobre a propriedade intelectual, considerando os termos do Agreement on Trade-Related Aspects of Intellectual Property Rights (TRIPS Agreement), da Organização Mundial do Comércio, os países concordavam em manter os correspondentes regimes de direitos e sistemas de aplicação. O objetivo era equilibrar as prerrogativas dos detentores dos direitos e os interesses dos usuários e da comunidade em geral.

A Parceria Trans-Pacífico (doravante PTP) tratada neste artigo representa uma expansão do acordo de 2005. Essa expansão é processo indissociável do envolvimento dos Estados Unidos a partir de 2009, primeiro ano do governo Obama, após manifestação de interesse no começo de 2008, ainda sob o governo de George W. Bush. As nego- 
ciações avançaram no primeiro trimestre de 2010, quando foram incorporados Austrália, Peru e Vietnã. A Malásia ingressou no final daquele ano, e Canadá e México aderiram em junho de 2012, totalizando onze países até o início de 2013 (Figura 1). Como interessados, mas ainda só na condição de observadores, perfilam-se Coreia do Sul, Filipinas, Japão e Taiwan. Essas negociações se encontram, portanto, em pleno andamento.

Os países efetivamente envolvidos até o início de 2013 possuíam, em conjunto, uma população de quase 657 milhões em 2011, 9,4\% do total mundial, que somava quase 6,97 bilhões. A desigualdade demográfica é gritante no interior do grupo. Enquanto os Estados Unidos registravam 311,6 milhões de habitantes, Brunei mal alcançava 406

\section{Figura 1}

Países em Negociação sobre a Parceria Trans-Pacífico - Janeiro de 2013

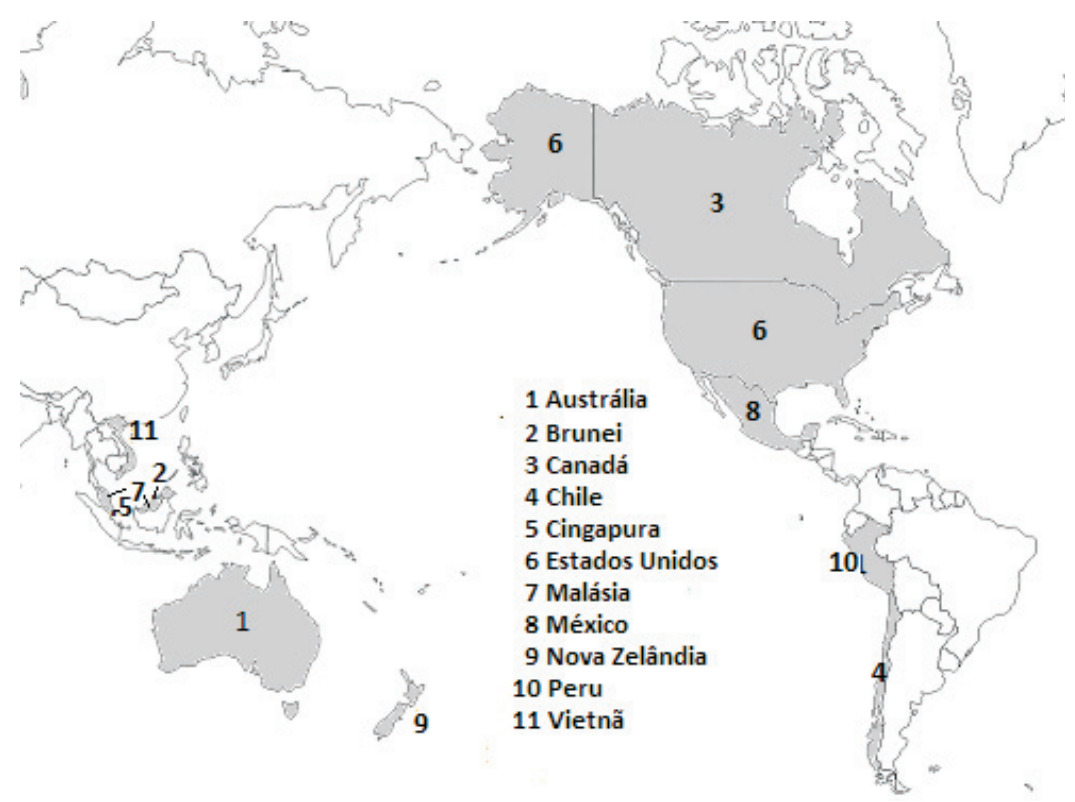

Fonte: Elaboração do autor com mapa disponível em: <http://d-maps.com/carte.php?lib=world_pacific_ocean_centered_map\&num_car=3231\&lang=en>. 
mil pessoas. O segundo país mais populoso é o México, e sua população equivalia só a 37\% do contingente dos Estados Unidos (Tabela1).

A presença econômica desse grupo de países em termos mundiais supera em muito a populacional (Tabela 2). Em 2011, o produto interno bruto (PIB), as exportações e as importações participaram dos totais planetários com 29,3\%, 19,6\% e 22,2\%, nessa ordem. Os Estados Unidos sobressaem enormemente, seguidos de longe por Canadá e Austrália quanto ao primeiro indicador, e por Canadá e Cingapura quanto aos demais. Mas a hierarquia é outra quando se olha o PIB per capita e, principalmente, quando se consideram os indicadores de abertura econômica. Seja pelo grau de abertura da economia ao exterior (GAEE) ou pela intensidade exportadora (IE), nenhum outro país sequer se aproxima dos quatro do Sudeste Asiático: Brunei, Cingapura, Malásia e Vietnã.

\section{Tabela 1}

Países da Parceria Trans-Pacífico: População em 2011

\begin{tabular}{l|r|c}
\hline Países & População & $\begin{array}{c}\text { Participação na } \\
\text { população mundial } \\
\text { (\%) }\end{array}$ \\
\hline Austrália & 22.620 .600 & 0,3 \\
Brunei & 405.938 & 0,006 \\
Canadá & 34.482 .779 & 0,5 \\
Chile & 17.269 .525 & 0,2 \\
Cingapura & 5.183 .700 & 0,07 \\
EUA & 311.591 .917 & 4,5 \\
Malásia & 28.859 .154 & 0,4 \\
México & 114.793 .341 & 1,6 \\
Nova Zelândia & 4.405 .200 & 0,06 \\
Peru & 29.399 .817 & 0,4 \\
Vietnã & 87.840 .000 & 1,3 \\
Total da Parceria Trans-Pacífico & 656.851 .971 & 9,4 \\
Mundo & 6.965 .944 .512 & 100,0 \\
\hline
\end{tabular}

Fonte: Elaboração do autor com dados do Banco Mundial, disponíveis em: <http://search.worldbank. org/data?qterm>. 


\section{Hoyêdo Nunes Lins}

\section{Tabela 2}

Países da Parceria Trans-Pacífico: Indicadores Selecionados sobre a Economia - 2011

\begin{tabular}{|c|c|c|c|c|c|c|c|c|c|}
\hline \multirow{2}{*}{$\begin{array}{c}\text { “Regiões" } \\
\text { /Países }\end{array}$} & \multicolumn{2}{|c|}{$\mathrm{PIB}^{\mathrm{a}}$} & \multirow{2}{*}{$\begin{array}{l}\text { PIB per } \\
\text { capita }^{b}\end{array}$} & \multicolumn{2}{|c|}{ Exportações $^{a}$} & \multicolumn{2}{|c|}{ Importações $^{a}$} & \multicolumn{2}{|c|}{ Abertura } \\
\hline & Abs. & $\%$ & & Abs. & $\%$ & Abs. & $\%$ & GAEE $^{c}$ & $\mathrm{IE}^{\mathrm{d}}$ \\
\hline \multicolumn{10}{|c|}{ América do Norte } \\
\hline Canadá & 1.736 & 2,5 & 50.345 & 541 & 2,4 & 562 & 2,6 & 63,5 & 31,2 \\
\hline EUA & 14.991 & 21,4 & 48.112 & 2.094 & 9,4 & 2.662 & 12,2 & 31,7 & 14,0 \\
\hline México & 1.153 & 1,6 & 10.047 & 365 & 1,6 & 381 & 1,7 & 64,7 & 31,7 \\
\hline \multicolumn{10}{|c|}{ América do Sul } \\
\hline Chile & 249 & 0,3 & 14.394 & 95 & 0,4 & 86 & 0,4 & 72,7 & 38,1 \\
\hline Peru & 177 & 0,2 & 6.018 & 51 & 0,2 & 44 & 0,2 & 53,7 & 28,7 \\
\hline \multicolumn{10}{|l|}{ Pacífico Sul } \\
\hline Austrália & 1.379 & 2,0 & 60.979 & 294 & 1,3 & 273 & 1,2 & 41,1 & 21,3 \\
\hline N. Zelândia & 160 & 0,2 & 36.254 & 48 & 0,2 & 46 & 0,2 & 58,7 & 30,0 \\
\hline \multicolumn{10}{|c|}{ Sudeste Asiático } \\
\hline Brunei & 16 & 0,02 & 40.301 & 13 & 0,06 & 5 & 0,02 & 112,5 & 81,3 \\
\hline Cingapura & 240 & 0,3 & 46.241 & 501 & 2,2 & 437 & 2,0 & 390,8 & 209,0 \\
\hline Malásia & 288 & 0,4 & 9.977 & 264 & 1,2 & 218 & 1,0 & 167,4 & 91,6 \\
\hline Vietnã & 124 & 0,2 & 1.407 & 108 & 0,5 & 113 & 0,5 & 178,2 & 87,0 \\
\hline Subtotal & 20.513 & 29,3 & 31.229 & 4.374 & 19,6 & 4.827 & 22,2 & 44,8 & 21,3 \\
\hline Mundo & 69.982 & 100 & 10.035 & 22.354 & 100 & 21.781 & 100 & 63,1 & 29,3 \\
\hline
\end{tabular}

Fonte: Elaboração do autor com dados do Banco Mundial, disponíveis em: <http://search.worldbank.org/data?qterm>.

a US\$ bilhões

b US $\$ 1,00$

${ }^{c}$ Grau de Abertura da Economia ao Exterior: Exportações + Importações/PIB * 100

d Intensidade Exportadora: Exportações/PIB * 100

Também na estrutura do comércio externo, incluindo a geografia dos respectivos vínculos, esse conjunto de países se mostra bastante heterogêneo. Informações sistematizadas pela Organização Mundial do Comércio ${ }^{1}$ revelam que os Estados Unidos, o Canadá e o México comercializam mais intensamente na sua própria região, embora a China e a União Europeia figurem entre os principais parceiros. Chile e Peru relacionam-se sobretudo com a China e a União Euro- 
peia, não obstante uma expressiva participação dos Estados Unidos nas compras externas de ambos. Austrália e Nova Zelândia têm na Ásia (destacando-se a China nas vendas e nas compras nos dois casos) e no sul do Pacífico os principais contextos do seu comércio externo, ainda que a União Europeia e os Estados Unidos também sobressaiam.

Com a exceção de Brunei quanto às exportações - trata-se de um pequeno sultanato petroleiro -, o intercâmbio comercial dos membros localizados no Sudeste Asiático incide majoritariamente na própria região. Mas esse comércio também envolve países como Japão e Coreia do Sul, além de alcançar a União Europeia e os Estados Unidos. Observe-se que a referida concentração regional reflete estratégias de "regionalização" produtiva, implicando divisão espacial do trabalho, praticadas por empresas asiáticas e ocidentais.

Cabe notar ainda que os membros originais da PTP - Brunei, Chile, Cingapura e Nova Zelândia - tendem a comercializar pouco entre si. Mesmo com o acordo de 2005, esses países não têm figurado entre os principais parceiros de cada um. Há uma única exceção: Cingapura constitui uma importante origem das importações de Brunei.

\section{Aspectos Econômicos da Parceria Trans-Pacífico: Alcance e Controvérsias}

O interesse dos Estados Unidos na PTP foi reafirmado antes que o ano inicial do primeiro mandato do presidente Obama tivesse terminado. Em novembro de 2009, esse chefe de Estado anunciou em Tóquio o engajamento do seu país em iniciativa regional que haveria de ter os "altos padrões dignos de um acordo comercial do século XXI" (OFFICE..., 2009). 
Desde então, a liderança das negociações em torno da PTP vem sendo exercida pelos Estados Unidos. É sugestivo que cinco das dezesseis rodadas formais, realizadas a partir de março de 2010 (quase uma cada dois meses, em média), tenham ocorrido em cidades desse país. A rodada mais recente, até o momento da elaboração deste texto, teve lugar em Cingapura, em março de 2013.

O vigoroso envolvimento do governo Obama guarda relação com o seu interesse em dobrar as exportações dos Estados Unidos em poucos anos, desde o início da sua primeira gestão (ASIA-PACIFIC..., 2012). Essa motivação pode causar surpresa, tendo em vista que esse país já possuía acordos de livre comércio com integrantes da PTP, envolvendo Canadá e México (North American Free Trade Agreement [NAFTA]) e, bilateralmente, Chile, Cingapura, Austrália e Peru. Todavia, diferentes acordos comerciais podem significar numerosas tarifas e regras de origem dos produtos - configurando o problema do spaghetti bowl da metáfora de Bhagwati (2003) -, fontes de altos custos de transação quando as empresas comercializam em vários mercados nacionais (HERREROS, 2011). A adesão dos países a um mesmo conjunto de regras tende, assim, a facilitar o comércio. De todo modo, um dos maiores desafios das negociações sobre a PTP diz respeito à articulação dos acordos já existentes entre pares ou em grupos de países envolvidos nessa iniciativa.

Seja como for, os membros da PTP não representam em bloco, antes da conclusão das tratativas, uma relação comercial de pouca importância para os Estados Unidos. Examinando dados de 2010, e sem considerar a participação de Canadá e México (pois as condições do NAFTA afetariam a observação), Fergusson e Vaughn (2011) assinalam que aquele conjunto se revela o quinto maior parceiro comercial desse país, figurando logo após o Japão e à frente da Alemanha. A expectativa é que a uniformização das regras tarifárias e de origem intensifique ainda mais esses vínculos, incrementando as exportações e os ganhos de renda para todos os participantes. Apontam nessa 
direção as simulações de Petri e Plummer (2012, p. 8), cujos "resultados oferecem uma forte base para os interesses dos Estados Unidos pelo livre comércio na Ásia-Pacífico".

Uma questão central do processo em estudo é que, ao assumir a liderança das negociações, os Estados Unidos introduziram na PTP elementos básicos do modelo de áreas de livre comércio que vem norteando suas ações gerais sobre esse assunto, em distintas circunstâncias. A experiência do NAFTA tem status paradigmático. Não por acaso, uma página na internet como a do Citizens Trade Campaign indaga se não estaria em curso, com a PTP, um "NAFTA for the Pacific Rim?". 2 Na mesma linha, articulistas falam, a propósito do projeto, em "NAFTA on steroids" (WALLACH, 2012), aludindo à incorporação de Canadá e México.

A orientação imprimida às negociações tem provocado fortes críticas e protestos. Agricultores japoneses foram às ruas em outubro de 2011 contra uma eventual participação daquele país, após o premier ter indicado uma possível adesão no futuro (WALLACH, 2012). Manifestações estridentes caracterizam diversas instituições da sociedade civil, como ilustrado pela mencionada Citizens Trade Campaign, que convocou demonstrações públicas quando da $14^{\underline{a}}$ rodada de negociações, ocorrida em setembro de 2012 em Leesburg, Virgínia(EUA). ${ }^{3}$ Cabe dizer o mesmo sobre a Electronic Frontier Foundation, que defende direitos no mundo digital - promotora da TPP Stop the Trap Petition, dirigida à United States Trade Representative - ${ }^{4}$ e sobre a Public Citizen's Global Trade Watch, ${ }^{5}$ que se preocupa com os danos para os cidadãos dos Estados Unidos.

Crítica corrosiva é observada também no ambiente acadêmico, em posições como a da neozelandesa Jane Kelsey. Examinando aspectos jurídicos, essa autora diz que não há "qualquer razão aparente para a Nova Zelândia adotar esse texto [rascunho do capítulo sobre investimentos, abordado posteriormente] e [que] há razões abundan- 
tes para não adotar" (KELSEY, 2012). Dean Baker, do Center for Economic and Policy Research (em Washington, D.C.), assinala que, a julgar pelo que se pode observar nos documentos sobre direitos de propriedade intelectual, as negociações sobre liberdade de comércio podem significar qualquer coisa, menos liberdade, tão grandes seriam os privilégios concedidos às grandes empresas (BAKER, 2012).

No centro dos ataques figura, em primeiro lugar, o segredo que envolve as negociações. De fato, os respectivos documentos, vazados na internet, trazem a advertência "Este documento contém informações CONFIDENCIAIS SOBRE A PTP”, com ênfase dada pelo uso de letras maiúsculas. As instituições interessadas em monitorar as tratativas não economizam palavras sobre o segredo. Há quem fale em "disfarçado ataque à democracia” (FORTHOFER, 2012), pois senadores estadunidenses tiveram negado o pedido de detalhes, enquanto representantes de grandes empresas têm atuado como advisors nas negociações, como informa Roberts (2012).

Os rascunhos de capítulos ou de trechos do acordo que foram vazados na internet galvanizam, de fato, o principal das atenções. Até o momento em que se escreve este artigo, e pelo que foi possível observar, esses documentos são os seguintes: Regulatory Coherence, ${ }^{6}$ texto de março de 2010; U.S. Introduction to Proposed TBT [Technical Barriers to Trade] Annexes on Medical Devices, Pharmaceutical Products and Cosmetic Products, ${ }^{7}$ de março de 2010; Intelectual Property Rights Chapter, ${ }^{8}$ de fevereiro de 2011; Transparency Chapter - Annex on Transparency and Procedural Fairness for Healthcare Technologies, ${ }^{9}$ de junho de 2011; Investment, ${ }^{10}$ um rascunho não datado; e Pre-grant Opposition, ${ }^{11}$ texto não datado sobre o questionamento prévio à concessão de patentes.

A natureza dessas fontes impõe alguns comentários. Os documentos em questão aparecem referidos em diferentes manifestações, acadê- 
micas ou não, sobre a PTP. Assim, têm sido utilizados por pesquisadores e outros analistas que se ocupam do assunto, assim como por instituições da sociedade civil atentas ao andamento das negociações. Isso foi constatado pelo cruzamento das referências, em distintas manifestações. O insucesso, durante a pesquisa, nas tentativas de encontrar esse material em outras esferas, como estruturas governamentais, fez com que a aproximação ao assunto - mencionado, por exemplo, pelo Office of the United States Trade Representative e objeto de análises no âmbito do Congresso dos Estados Unidos (FERGUSSON; VAUGHN, 2011) e mesmo da Comissão Econômica para a América Latina e o Caribe (HERREROS, 2011) - se escorasse nessas fontes, fundamentalmente.

Algumas das questões mais polêmicas das negociações, conforme observado no manuseio desse material, encontram-se no rascunho do capítulo sobre Regulatory Coherence, onde se indica (no item 2.b do primeiro artigo) que cada país terá o "direito soberano de identificar suas prioridades regulatórias e estabelecer e implementar medidas regulatórias para atingir essas prioridades, nos níveis em que um membro julgar apropriados". Entretanto, os nove artigos que formam o documento, alguns com muitos desdobramentos internos, representam uma efetiva agenda de mudanças nas práticas regulatórias dos países. Operacionalizar as alterações, nos termos em negociação, anuncia-se como um enorme desafio. A razão é que, como salientado por Petri e Plummer (2012, p. 3), os modelos de acordos negociados pelos Estados Unidos costumam privilegiar "enfoques baseados em regras que são comuns em um ambiente institucional de país desenvolvido", mas que se revelam de difícil implantação em outros tipos de países.

É também de regulação que trata o texto U.S. Introduction to Proposed TBT [Technical Barriers to Trade] Annexes on Medical Devices, Pharmaceutical Products and Cosmetic Products, destinado ao capítulo sobre barreiras técnicas ao comércio, e o Transparency Chap- 
ter-Annex on Transparency and Procedural Fairness for Healthcare Technologies.

No primeiro, a intenção é alinhar os regimes regulatórios dos países sobre a comercialização de equipamentos médicos, produtos farmacêuticos e cosméticos. A obrigação dos signatários em colaborar nessa direção é um aspecto central da proposta. Cabe também sublinhar que se indica ser compulsório o aceite da regulamentação definida no âmbito da ICH (sigla para International Conference on Harmonization of Technical Requirements for Registration of Pharmaceuticals for Human Use). Tal regulamentação deve ser adotada apesar da sua insuficiência: lê-se, no item 9, que um país-membro "aceitará informações sobre segurança, eficácia e qualidade de fabricação submetidas em um formato consistente com os princípios do Common Technical Document (CTD) do ICH, reconhecendo que o CTD não necessariamente cobre todos os aspectos relevantes para a decisão [...] de autorizar a venda de um produto particular".

No capítulo sobre transparência, no anexo que trata da clareza dos procedimentos em relação aos cuidados com a saúde, abordam-se questões ligadas à comercialização de medicamentos e equipamentos médicos. O parágrafo $3^{\underline{0}}$ exibe particular envergadura, dedicando atenção às situações em que, mantendo programas públicos de saúde, governos relacionam produtos farmacêuticos e equipamentos médicos e definem reembolsos relativamente a tais produtos e equipamentos. É significativo que os correspondentes termos de negociação tenham gerado grande inquietação, sobretudo na Austrália e na Nova Zelândia, que possuem programas nacionais de acesso facilitado da população a produtos farmacêuticos com preços menores. O temor, expresso em diferentes manifestações, é de que a PTP possa comprometer esse tipo de ação governamental nos países-membros (ver, por exemplo, WALLACH, 2012).

Contudo, as maiores críticas de todos os que se debruçam sobre as negociações se referem às propostas sobre propriedade intelectual e 
sobre investimentos. É com base nos respectivos documentos que se diz ser a PTP, antes de acordo comercial, um instrumento de favorecimento às grandes empresas, em detrimento das populações. Roberts (2012), por exemplo, entende que a PTP representará nada menos do que um "privilégio global para a classe corporativa como uma classe imune à regulação governamental”.

Cabe assinalar desde logo que a forma como os Estados Unidos abordam a questão da propriedade intelectual reflete a condição desfrutada por esse país na oferta mundial de bens e serviços nos quais incidem os correspondentes direitos. Os Estados Unidos têm defendido vigorosamente esses direitos, ao ponto de elaborar listas de países cuja conduta é considerada reprovável à luz das suas próprias leis (HINZE, 2010).

Esse enfoque transparece no artigo $4^{\underline{0}}$ do respectivo documento, que não só aborda com detalhes a questão do copyright, como aponta formas de penalização dos infratores. Os países-membros são instados a defender esses direitos na direção apontada, no tocante a definições, proibições e controle. Sobre patentes, tratadas no longo artigo $8^{\underline{o}}$, o capítulo traz indicações de como os países devem se adequar e conduzir, merecendo realce o que se prevê para produtos farmacêuticos, esmiuçado em texto aparentemente negociado à parte, visto que destacado do corpo principal do capítulo: ${ }^{12}$ uma proteção de patentes ainda mais forte e prolongada do que prevê a Organização Mundial do Comércio, e maior exclusividade sobre informações de produtos, o total representando maiores privilégios para as grandes empresas (BAKER, 2012).

Também longos e densos são os artigos sobre procedimentos e soluções nos planos cível e administrativo (art. 12) e sobre imposição criminal (art. 15). Em conjunto, tais dispositivos significam exigências de adaptação dos sistemas legais dos países e de adoção, por autoridades policiais e judiciárias, de padrões de conduta aptos a controlar, 
coibir e penalizar os infratores. A base dessas propostas é, provavelmente, a própria estrutura existente nos Estados Unidos sobre a questão. Não é certo, todavia, que tal modelo possa funcionar em países como, por exemplo, Brunei e Vietnã, carentes da atmosfera institucional que caracteriza, entre outros, Estados Unidos e Canadá.

Devem ser igualmente destacadas as medidas sobre direitos de propriedade intelectual no ambiente digital (art. 16). O teor do capítulo como um todo, inclusive no que concerne às questões de imposição criminal, incide também nesses direitos. Bastante detalhado, o texto prevê diversas situações em que provedores de serviços no ambiente digital poderão ser acionados judicialmente (indicam-se até casos de suavização do corretivo). O rechaço por grupos da sociedade civil inclui expressões como "Não deixe que eles negociem nossas liberdades na internet" (ROSSINI; SUTTON, 2012), e ainda campanhas para coleta de assinaturas para bloquear ações na PTP que prejudiquem o uso da internet.

No capítulo que rege os investimentos realizados por agentes de um país-membro em outros da PTP, chama a atenção, em primeiro lugar, a ampla definição do seu objeto. Pelo artigo $2^{\underline{0}}$, seriam investimentos até "licenças, autorizações, permissões e direitos similares conferidos de acordo com a lei doméstica". Nesses termos, já teria direitos de investidor quem só dispusesse de uma autorização para investir. Também cabe realçar a exigida presteza nas restituições e compensações aos investidores (art. $6^{\underline{0}}$ ) quando ocorrer requisição (ou destruição) de investimentos por autoridades ou forças militares dos países receptores dos investimentos, em casos de guerra ou conflitos civis.

No trato com investidores de outros países, nenhum signatário poderá exigir: exportação de qualquer fração dos bens ou serviços produzidos; presença de conteúdo doméstico; compra ou uso de bens nacionais; vinculação do volume importado ao volume exportado ou à entrada de divisas por conta do investimento; quantidade ou valor de 
exportações ou de entrada de divisas como determinante do valor das vendas domésticas; transferência de tecnologia, processo produtivo ou algum outro tipo de conhecimento (art. $7^{\underline{0}}$ ). Os benefícios aos investidores abrangem transferências financeiras, cujo fluxo será livre e sem atraso (art. 11). Todas as transferências desse tipo são contempladas, admitindo-se restrição só em casos de falência, insolvência ou proteção a credores.

As maiores críticas dirigem-se à seção B do capítulo, intitulada Investor-State Dispute Settlement, sendo significativa a posição da Austrália nas vinculadas negociações: a nota de rodapé $n^{0}-20$ diz que o tópico não se aplica a esse país, que "não aceita a submissão de um pedido de arbitragem nos termos desta seção".

$\mathrm{O}$ art. 18 estipula em seis meses o prazo máximo para resolução de uma disputa desse tipo. Se isso não ocorrer, o reclamante (uma empresa) pode solicitar arbitragem sobre ato do reclamado (um país-membro) por quebra seja de obrigação, de autorização para investimento ou de concordância sobre investimento, com as perdas e os danos decorrentes. A demanda pode ser submetida no marco da ICSID Convention ${ }^{13}$ e da ICSID Rules of Procedure for Arbitration Proceedings, ou no da ICSID Additional Facility Rules, se reclamado e reclamante forem aderentes à ICSID Convention. Mas a submissão pode também ocorrer sob as UNCITRAL Arbitration Rules, ${ }^{14}$ ou, se reclamante e reclamado concordarem, ser dirigida a qualquer outra instituição de arbitragem e ser formulada por quaisquer outras regras.

Todos os países devem aceitar a arbitragem, com tribunais de três membros, que representam uma indicação de cada parte e um terceiro (apontado por acordo) na condição de presidente. Porém, pela ICSID Convention - instituição aparentemente privilegiada na proposta, a julgar pela quantidade de referências -, se um tribunal não for constituído em 75 dias a contar do pedido de arbitragem, o secre- 
tário-geral dessa instituição indicará o(s) árbitro(s) ainda não apontado(s). O parágrafo $4^{\underline{0}}$ do art. 21 (sobre a seleção de árbitros) mostra o significado desse enquadramento institucional para os países demandados judicialmente: se não existir outra base de objeção à pessoa designada, além da nacionalidade do árbitro, "o reclamado concorda com a indicação de cada membro individual de um tribunal estabelecido sob a ICSID Convention ou a ICSID Additional Facility Rules".

Kelsey (2012) assinala que, nesse tipo de tribunal, onde não se prestam contas, “não há recurso e os ‘juízes' são principalmente advogados da área de investimentos que também atuam para clientes submetendo tais requerimentos". Assim, se uma política (de proteção ambiental, por exemplo) executada em um país da PTP for considerada prejudicial aos interesses de uma empresa vinda de outro país-membro, uma ação judicial da segunda contra o primeiro poderá ser apreciada em um tribunal off-shore, desvinculado do sistema de corte doméstico. É a isso que Wallach (2012) se refere ao falar em "sistema legal paralelo". Ademais, dar às grandes empresas "o direito de fazer governos pagá-las pelo custo de cumprir os regulamentos governamentais" (ROBERTS, 2012) logo haverá de suscitar indagações sobre "quanto tempo a regulação ambiental, trabalhista e financeira pode sobreviver, quando os custos de cumprimento são impostos aos contribuintes e não à atividade econômica que resulta em spillover effects, como poluição" (ROBERTS, 2012).

\section{Perscrutando o Sentido Geopolítico da Motivação Estadunidense em Relação à Parceria Trans-Pacífico}

A proeminência adquirida pela região Ásia-Pacífico na economia mundial parece ter sido um fator central na decisão dos Estados Unidos relativamente à participação em acordo comercial envolvendo 
países nas duas margens do Oceano Pacífico. Essa motivação teria sido potencializada, segundo Petri e Plummer (2012), pelo fato de a Association of Southeast Asian Nations (Asean) ter registrado, nas últimas décadas, numerosos acordos restritos à Ásia e que frequentemente envolvem países como China, Japão e Coreia do Sul, pontas de lança do dinamismo econômico regional.

A China distingue-se de longe entre tais países, exibindo uma "importância regional cada vez maior [...] em detrimento dos Estados Unidos" (ARRIGHI, 2008, p. 216). Esse grande destaque, que é antes de tudo econômico, porém igualmente observado no front geopolítico, cresceu a olhos vistos. A China teria passado a eclipsar, de algum modo, a influência regional dos Estados Unidos mesmo em termos culturais, como diz Arrighi (2008), que faz referência à crescente atração exercida pela primeira até junto a turistas e universitários, algo também associado às dificuldades para a entrada de estrangeiros no segundo, na esteira dos eventos de 11 de setembro de 2001.

Portanto, não parece haver equívoco no entendimento segundo o qual se mostrou crescentemente necessário, para os Estados Unidos, assegurar uma presença econômica ainda mais integral e substantiva na região Ásia-Pacífico. Para diferentes observadores, descuidar disso "deixaria os Estados Unidos em desvantagem na mais dinâmica região da economia mundial e enfraqueceria os fortes vínculos de segurança que esse país tem mantido com o Leste Asiático desde o fim da Segunda Guerra Mundial" (HERREROS, 2011, p. 19).

O risco de marginalização foi reconhecido no próprio Congresso desse país. Documento elaborado no âmbito desse órgão evidencia tal percepção e reflete, de alguma maneira, a forma como a PTP passou a ser encarada em esferas institucionais dessa importância.

O temor entre alguns analistas de política e comércio, de que os Estados Unidos corriam o risco de marginalização por não responderem à 
proliferação de acordos comerciais que emergiram na Ásia nos anos recentes, parece ter sido um fator-chave por trás das decisões sobre um engajamento mais completo em arquiteturas regionais asiáticas, incluindo a PTP (FERGUSSON; VAUGHN, 2011, p. 2).

Assinale-se que não é somente em escala de região Ásia-Pacífico que os riscos à posição ocupada pelos Estados Unidos, tendo em vista o fortalecimento econômico de outros países (a China em particular), suscitam reflexão e debate. Com efeito: "O desafio central dos Estados Unidos nas próximas várias décadas é revitalizar-se, ao mesmo tempo em que [...] sustentam um equilíbrio complexo no Oriente que possa acomodar o crescente status global da China" (BRZEZINSKI, 2012, p. 97). De toda maneira, o anúncio sobre a entrada dos Estados Unidos nas negociações da PTP, feito pelo presidente Obama em Tóquio, em novembro de 2009, inscreveu-se em sequência de visitas e discursos governamentais cujo assunto principal foi a diversificação e o fortalecimento dos vínculos entre aquele país e estados da região Ásia-Pacífico.

Em novembro de 2011, Obama anunciou no Parlamento australiano que o retorno estadunidense à região era "para ficar". Crivado de referências aos problemas de segurança, o discurso informou sobre a instalação de unidades rotativas de marines no norte da Austrália. No mesmo mês, a então secretária de Estado, Hillary Clinton, comunicou em Manila que os Estados Unidos atualizariam suas relações com cinco aliados da região (Austrália, Japão, Filipinas, Coreia do Sul e Tailândia), evocando uma aliança militar formada em 1951, o ANZUS Treaty (WE'RE..., 2011). A Declaração de Manila, adotada nessa ocasião, significou basicamente um compromisso de estreitamento de vínculos militares entre Estados Unidos e Filipinas.

Mas os movimentos protagonizados foram além, haja vista que, simultaneamente, 
[...] a Casa Branca anunciou a venda de 24 aviões de combate F-16 à Indonésia e uma visita de Hillary Clinton à isolada Birmânia, uma velha aliada da China, a primeira visita de um secretário de Estado estadunidense em 56 anos. Clinton também falou sobre uma maior aproximação diplomática e militar com Cingapura, Tailândia e Vietnã, todos eles países vizinhos da China ou em rotas de comércio chaves para a importação de matérias-primas e a exportação de produtos manufaturados.

No modo apresentado pelos funcionários do poder executivo estadunidense, essas ações estão destinadas a maximizar as vantagens dos Estados Unidos nos âmbitos diplomático e militar em um momento em que a China domina o âmbito econômico regional (KLARE, 2011, p. 2).

Todavia, nada parece sistematizar melhor o modo como os Estados Unidos consideram atualmente a região Ásia-Pacífico do que o artigo da ex-secretária de Estado publicado pela revista Foreign Policy em novembro de 2011 (CLINTON, 2011). Enfatizando, de forma praticamente contínua, a importância da segurança e da paz, o texto apresenta-se, em essência, como uma enfática argumentação sobre o papel dos Estados Unidos na garantia de ambas, apontadas como alicerces básicos da saliência econômica e política lograda regionalmente e indicadas, por extensão, como requisitos para a manutenção do nível de desempenho atingido.

Tem realce no artigo a ideia de que o forte envolvimento dos Estados Unidos nos processos em curso naquela região produzirá resultados capazes de assegurar a manutenção da liderança mundial desse país no presente século. Na perspectiva apresentada, os Estados Unidos usufruirão, com o crescimento da sua presença regional, de oportunidades sem precedentes em termos de investimentos, comércio e 
acesso à tecnologia de ponta. Mais ainda, segundo a abordagem, o aproveitamento da grande e crescente base de consumo da Ásia se revelará um fator decisivo para a recuperação econômica daquele país no plano doméstico.

Mas a concretização desses benefícios dependerá, considera a autora, de ações preventivas para manter a paz e a segurança, incluindo a garantia da livre navegação no Mar do Sul da China e a contenção das ameaças da Coreia do Norte. Daí a opção pelo que é indicado como "virada estratégica para a região" por parte dos Estados Unidos. Uma diplomacia nesse sentido, de caráter permanente em todas as latitudes da região Ásia-Pacífico, é vista como instrumento básico a ser empregado. Entre suas principais linhas estaria o fortalecimento de relações bilaterais envolvendo segurança, assim como o estabelecimento de uma presença militar de ampla base.

Esse fortalecimento implica atualizar alianças já existentes (com Japão, Coreia do Sul, Austrália, Filipinas e Tailândia), as quais têm representado, segundo o texto, um importante e duradouro substrato do ambiente que favoreceu o forte crescimento da região. Para os Estados Unidos, essas alianças representam suporte à sua presença e à sua liderança na região, um atributo imprescindível perante os crescentes desafios da atualidade, conforme a argumentação. Não por acaso, ações para fortalecer essas alianças têm sido realizadas, de acordo com a então secretária de Estado.

Mas novas parcerias também são necessárias, uma direção na qual os Estados Unidos já se encontrariam trabalhando, como assinalado sobre a Índia e a Indonésia. A mais estratégica dessas novas parcerias diz respeito à China, país que, segundo os termos apresentados,

[...] prosperou como parte do sistema aberto e baseado em regras que os Estados Unidos ajudaram a construir e atuam para sustentar. E, hoje, a China representa uma das relações bilaterais mais desafiadoras e consequentes que os 
Estados Unidos já tiveram que conduzir. Isso requer uma administração cuidadosa, constante e dinâmica, um enfoque de nossa parte para a China que seja baseado na realidade, focado em resultados e fiel aos nossos princípios e interesses (CLINTON, 2011).

Segundo a então secretária de Estado, apesar dos temores e suspeitas de lado a lado, o atual governo dos Estados Unidos considera que a prosperidade do seu país é benéfica para a China e vice-versa. Assim, é de aprofundamento da cooperação que se trata, e não de confrontação.

Faz-se necessário, entretanto, evoluir das palavras às ações. Realizações nesse sentido têm sido observadas em planos tão diversos como os da segurança e da economia. Porém, ainda há muito por fazer. Os contemplados avanços exigiriam medidas na forma de, por exemplo, reformas chinesas em áreas como concorrência e proteção dos direitos de propriedade intelectual, assim como no plano cambial, extensivas aos direitos humanos e ao sistema político. Providências nessa direção, frisa a autora, aumentariam a confiança dos parceiros internacionais e conformariam a base para um crescimento ainda maior e uma mais forte estabilidade social e política.

Para além das relações bilaterais, a sublinhada "virada estratégica para a região", por parte dos Estados Unidos, implica cooperação multilateral envolvendo instituições como a Asean e a APEC. Ações nesse sentido foram executadas por aquele país, devendo-se realçar os propósitos quanto à segunda instituição, que abrange toda a orla do Pacífico: o governo estadunidense estaria empenhado em fazer da APEC a principal instituição econômica da região Ásia-Pacífico, objetivo que exige fixar "a agenda econômica de forma a colocar juntas as economias avançadas e emergentes para promover o comércio aberto e os investimentos, assim como construir capacidade e promover regimes regulatórios" (CLINTON, 2011). Abordar a APEC 
dessa maneira condiz com a orientação daquele governo a respeito do entrelaçamento da promoção econômica pelo aparato estatal [statecraft] com a política externa: "Cada vez mais, o progresso econômico depende dos vínculos diplomáticos e o progresso diplomático depende de vínculos econômicos fortes" (CLINTON, 2011), assinala a autora do artigo.

A participação dos Estados Unidos em negociações comerciais na atualidade espelha essa visão. Isso é verdade tanto nos acordos bilaterais como nos mais abrangentes, como é o caso da Parceria Trans-Pacífico, a qual, em virtude dos seus "altos padrões" - nos termos utilizados pelo presidente Obama no mencionado discurso em Tóquio -, gera nesse governo a expectativa de se tornar "referência para acordos futuros - e crescer para servir como plataforma para uma mais ampla interação regional e, eventualmente, uma área de livre comércio da Ásia-Pacífico" (CLINTON, 2011).

Mas a autora adverte que o florescimento dessa potencialidade regional depende, como dependeu o forte crescimento da área em termos históricos, da segurança e da estabilidade longamente asseguradas pela presença militar dos Estados Unidos. Os desafios com que se depara essa região requerem uma melhor distribuição geográfica e uma maior flexibilidade operacional das forças militares desse país, para não falar de sustentabilidade política às iniciativas com tais objetivos. Ao que parece, movimentos nessa direção já estariam ocorrendo, embora permaneça a necessidade de uma conexão mais adequada, em termos de capacidade militar, entre os oceanos Pacífico e Índico, uma questão operacional assinalada no artigo da ex-secretária de Estado como nada menos que crucial.

O artigo termina quase apoteoticamente, após afirmar que outras regiões do mundo continuam vitais para os interesses dos Estados Unidos e clamam pela presença e liderança desse país. 
E nós estamos preparados para liderar. [...] [Aos que hoje questionam, cabe dizer que] sempre que os Estados Unidos experimentaram reveses, nós os superamos mediante reinvenção e inovação. Nossa capacidade de voltar mais forte é inigualável na história moderna. Isso deriva do nosso modelo de livre democracia e livre empresa, um modelo que permanece a mais poderosa fonte de prosperidade e progresso conhecida pela humanidade. [...] Nossa força militar é de longe a mais forte, e nossa economia é de longe a maior do mundo. [...] Assim, não deveria existir dúvida de que os Estados Unidos são capazes de garantir e sustentar nossa liderança global neste século, como fizemos no último (CLINTON, 2011).

Esse arremate tem a aparência de resposta a elaborações como a de Fishman (2004), que se referiu ao século XXI como o século chinês. De qualquer modo, a ênfase em questões de natureza militar, nas manifestações de autoridades estadunidenses, repercutiu na Ásia-Pacífico, e inquietações sobre como os Estados Unidos estariam a encarar o crescente poderio chinês instalaram-se na região. Na China, ressurgiu o alarme ativado pela postura beligerante em relação ao país observada no segundo mandato de George W. Bush. No âmago daquela conduta, figuraram a ascensão econômica e político-militar chinesa e a percepção dos Estados Unidos sobre os associados desafios e ameaças (ARRIGHI, 2008).

Assim, o tom que revestiu a assinalada "virada estratégica" dos Estados Unidos com respeito àquela região fez a Parceria Trans-Pacífico ser interpretada, em vários meios, como tentativa estadunidense para conter o notável desempenho comercial chinês. O principal ingrediente geopolítico da participação estadunidense estaria, assim, delineado. Por essa razão, tendo em vista que "acordos de livre comércio geralmente têm objetivos geopolíticos” (PETRI; PLUMMER, 2012, 
p. 2), não surpreende que a PTP venha enfrentando a "intensa suspeição de ser uma aliança de segurança disfarçada de negociação comercial" (ANOTHER..., 2012).

Cabe observar que o desconforto gerado pela ênfase em questões de segurança, nas manifestações de autoridades dos Estados Unidos sobre a região, parece ter influenciado as condutas posteriormente. Em julho de 2012, Hillary Clinton informou, em encontro de executivos no Camboja, que os Estados Unidos pretendiam dinamizar o seu comércio e acelerar o ritmo de seus investimentos na Ásia, especialmente no Sudeste Asiático. O destaque dado nessa ocasião aos problemas de natureza econômica foi interpretado como tentativa de matizar o que fora reconhecido, em distintos ambientes, como excessivo realce ao componente militar no enfoque estadunidense para a Ásia (PERLEZ, 2012).

\section{Considerações Finais}

Não parece exagero afirmar que as negociações em torno da Parceria Trans-Pacífico se destacam entre os processos contemporâneos capazes de afetar consideravelmente a paisagem econômica e política mundial neste limiar do século XXI. As razões dessa influência incluem, além da abrangência geográfica do acordo, a amplitude e a complexidade das questões contempladas.

Apresentar e discutir os termos das negociações, ressaltando os seus aspectos mais polêmicos, foi um dos objetivos deste artigo. Assinalou-se no texto que, tendo em vista o caráter controverso de várias propostas, as tratativas têm provocado a mobilização de grupos da sociedade civil. Questionando uma orientação nas negociações que estaria a contemplar muito mais, segundo distintos observadores, os benefícios das grandes corporações, os movimentos de mobilização invocam a defesa dos interesses dos cidadãos. 
A postulada capacidade de vincar o panorama político e econômico parece gerar inquietação, entre grupos da sociedade civil e em diversos países, também pelo fato de a PTP ser vista pelo governo dos Estados Unidos como uma espécie de referência para futuras ações do gênero. O caráter sigiloso e mesmo, como salientam alguns observadores, pouco democrático das negociações se mostraria especialmente preocupante. Assinalou-se, de fato, que nas manifestações críticas se lamenta existir espaço de participação para as grandes corporações sem contrapartida à altura para a representação política da sociedade.

Outro objetivo do artigo foi explorar o sentido geopolítico do envolvimento, com liderança, dos Estados Unidos. O dinamismo econômico da região Ásia-Pacífico, capitaneado pela China, e a proliferação de acordos comerciais intrarregionais, nos quais é recorrente a participação das economias mais pujantes, perfilam-se entre os fatores que, segundo diferentes observadores, impulsionaram a busca de uma maior presença regional por parte dos Estados Unidos, sob pena de ficarem em desvantagem. Não há dúvida de que o "fator China", com os desafios incrustados, figura no centro das motivações.

A PTP representaria, assim, um vetor - de grande relevância - dessa “reaproximação" dos Estados Unidos à região Ásia-Pacífico, ao lado de outros elementos, como sugerido pelos movimentos protagonizados nos últimos anos por autoridades desse país. Marcar presença efetiva em quadrante do planeta no qual o poderio chinês só faz ganhar em envergadura parece uma clara motivação para o envolvimento dos Estados Unidos em acordo com a abrangência e as implicações da PTP.

De outra parte, se a PTP carrega a condição de repercutir em escala mundial, como se entende neste artigo, o assunto em foco haverá de interessar mesmo em países não diretamente envolvidos. Sobretudo pelo seu peso em escala de América Latina, o Brasil é um desses paí- 
ses. Assim, estudos prospectivos, envolvendo a construção de possíveis cenários, sobre os reflexos da intensificação das relações comerciais entre os países da parceria, acompanhada de uma provável reconfiguração dos fluxos de investimentos internacionais, deveriam ter lugar em agendas institucionais e acadêmicas do país. Essa temática se mostraria tanto mais importante na medida em que outros países da região, como Japão e Coreia do Sul - atualmente somente observadores -, se incorporassem ao processo.

No mesmo diapasão, haveria de figurar entre as indagações o que pode significar o envolvimento de países latino-americanos nessa parceria, com vínculos que não incidirão diretamente sobre outros países do subcontinente. Tem-se em mente os reflexos sobre iniciativas regionais cujo objetivo é promover a harmonização política, a articulação ou a integração, quer em escala de América do Sul - com a União das Nações Sul-Americanas (Unasul), criada em 2008 -, quer de maneira mais abrangente - com a Comunidade de Estados Latino-americanos e Caribenhos (CELAC), estabelecida em 2010.

\section{Notas}

1. Informações encontradas na página da Organização Mundial do Comércio, disponível em: <http://stat.wto.org/CountryProfile/WSDBCountryPFView. aspx ?Language $=\mathrm{E}>$.

2. A página na internet da Citizens Trade Campaign, com a indagação referida, é: <http://www.citizenstrade.org/ctc/trade-policies/tpp-potential-trade-policy-problems/>.

3. A convocação de demonstrações públicas contra a Parceria Trans-Pacífico, durante a 14 $4^{\underline{a}}$ rodada de negociações, encontra-se na página da Citizens Trade Campaign: <http://www.citizenstrade.org/ctc/wp-content/uploads/2012/09/ TPPLeesburgReportersMemo.pdf $>$. 
Parceria Trans-Pacífico: Novas Geometrias no Capitalismo Global

4. A página da Electronic Frontier Foundation na internet, com a TPP Stop the Trap Petition, é: <https://www.eff.org/deeplinks/2012/07/tpp-stop-trappetition>.

5. Referência ao monitoramento das negociações pela Public Citizens Global Trade Watch, objetivando salvaguardar a situação de cidadãos dos Estados Unidos, consta da seguinte página na internet: <http://www.citizen.org/Page. aspx?pid=3129>.

6. O texto intitulado Regulatory Coherence encontra-se disponível na página da Citizens Trade Campaign: <http://www.citizenstrade.org/ctc/wp-content/ uploads/2011/10/TransPacificRegulatoryCoherence.pdf $>$.

7. O documento U.S. Introduction to Proposed TBT [Technical Barriers to Trade] Annexes on Medical Devices, Pharmaceutical Products and Cosmetic Products está disponível na página da Citizens Trade Campaign: $<$ http://www. citizenstrade.org/ctc/wp-content/uploads/2011/10/TransPacificTBTwMedicalAnnexes.pdf $>$.

8. O Intelectual Property Rights Chapter encontra-se disponível em: <http:// keionline.org/sites/default/files/tpp-10feb2011-us-text-ipr-chapter.pdf>.

9. O Transparency Chapter - Annex on Transparency and Procedural Fairness for Healthcare Technologies foi obtido na seguinte página da Citizens Trade Campaign: <http://www.citizenstrade.org/ctc/wp-content/uploads/2011/ 10/TransPacificTransparency.pdf $>$.

10. O texto Investment está disponível em: <http://tinyurl.com/tppinvestment>.

11. O documento intitulado Pre-grant Opposition está disponível em: $<\mathrm{http} / / /$ www.citizen.org/documents/Leaked-US-TPPA-paper-on-eliminating-pregrant-opposition.pdf $>$.

12. Material sobre direito de propriedade intelectual envolvendo principalmente patentes de produtos farmacêuticos encontra-se disponível em: <http:// www.citizenstrade.org/ctc/wp-content/uploads/2011/10/TransPacific IP1.pdf>.

13. ICSD Convention significa Convention on the Settlement of International Investment Disputes between States and Nationals of other States, realizada em Washington em março de 1965.

14. UNCITRAL significa United Nations Commission on International Trade Law, cujas regras de arbitragem foram adotadas em abril de 1976. 


\section{Referências Bibliográficas}

ANOTHER Ambitious Trade Agreement Gets Bogged Down. The Economist, 22 Sep. 2012. Disponível em: <http://www.economist.com/node/ 21563292>. Acesso em: 15 jan. 2013.

ARRIGHI, A. Adam Smith em Pequim: origens e fundamentos do século XXI. São Paulo: Boitempo, 2008.

ASIA-PACIFIC Forum to Cut Import Duties for Green Technologies. The New York Times, 7 Sep. 2012. (Energy \& Environment). Disponível em: $<$ http://www.nytimes.com/2012/09/08/business/energy-environment/asia-pacific-forum-to-cut-import-duties-for-green-technologies.html?_r=0>. Acesso em: 16 jan. 2013.

BAKER, D. The Pacific Free Trade Deal that's Anything but Free. The Guardian, 27 Aug. 2012. Disponível em: <http://www.guardian.co.uk/commentisfree/2012/aug/27/pacific-free-trade-deal>. Acesso em: 16 jan. 2013.

BHAGWATI, J. Testimony - Subcommittee on Domestic and International Monetary Policy, Trade and Technology. U.S. House of Representatives, Committee on Financial Services, $1^{\circ}$ Apr. 2003. Disponível em: <http://academiccommons.columbia.edu/catalog/ac\%3A123533>. Acesso em: 25 jan. 2013.

BRZEZINSKI, Z. Balancing the East, Upgrading the West. Foreign Affairs, v. 91, n. 1, p. 97-104, Jan./Feb. 2012. (Special Anniversary Issue: The Clash of Ideas).

CLINTON, H. America's Pacific Century. Foreign Policy, Nov. 2011. Disponível em: <http://www.foreignpolicy.com/articles/2011/10/11/americas_pacific_century>. Acesso em: 19 jan. 2013.

FERGUSSON, I. F.; VAUGHN, B. The Trans-Pacific Partnership Agreement. Washington: Congressional Research Service, Report for Congress, 12 Dec. 2011.

FISHMAN, T. C. The Chinese Century. The New York Times, 4 Jul. 2004. Disponível em: <http://www.nytimes.com/2004/07/04/magazine/the-chinesecentury.html?pagewanted=all\&src=pm>. Acesso em: 18 jan. 2013. 
FORTHOFER, R. Peace Train: Trans-Pacific Partnership a Disguised Attack on Democracy. Colorado Daily.Com, 6 Dec. 2012. Disponível em: <http:// www.coloradodaily.com/your-take/ci_20913137\#axzz2I8zrZK2W>. Acesso em: 14 jan. 2013.

HERREROS, S. The Trans-Pacific Strategic Economic Partnership Agreement: A Latin American Perspective. Santiago do Chile: Nações Unidas/ECLAC, Mar. 2011.

HINZE, G. Shaping IP Laws by not-so-Gentle Persuasion: The Special 301 Report. Electronic Frontier Foundation, 21 Apr. 2010. Disponível em: <https:// www.eff.org/deeplinks/2010/04/shaping-ip-laws-not-so-gentle-persuasionspecial>. Acesso em: 22 jan. 2013.

KELSEY, J. National Says "Yes" to Investor Rights to Sue. Scoop Independent News, 6 Jun. 2012. Disponível em: <http://www.scoop.co.nz/stories/ PO1206/S00186/national-says-yes-to-investor-rights-to-sue.htm>. Acesso em: 28 jan. 2013.

KLARE, M. T. Jugando con fuego. Obama amenaza a la China. Sin Permiso, 11 dez. 2011. Disponível em: <http://www.sinpermiso.info/textos/index. php?id=4619>. Acesso em: 22 jan. 2013.

OFFICE of the United States Trade Representative. TPP Statements and Actions to Date. Announcement by President Barack Obama, 14 Nov. 2009. Disponível em: <http://www.ustr.gov/about-us/press-office/fact-sheets/2009/december/tpp-statements-and-actions-date>. Acesso em: 25 jan. 2013.

PERLEZ, J. Clinton Makes Effort to Rechannel the Rivalry with China. The New York Times, 7 Jul. 2012. Disponível em: <http://www.nytimes. com/2012/07/08/world/asia/for-clinton-an-effort-to-rechannel-the-rivalrywith-china.html?_r=0>. Acesso em: 8 jan. 2013.

PETRI, P. A.; PLUMMER, M. G. The Trans-Pacific Partnership and Asia-Pacific Integration: Policy Implications. Washington: Peterson Institute for International Economics. Policy Brief, n. PB 12-16, Jun. 2012.

ROBERTS, P. C. Trans Pacific Partnership: Corporate Escape from Accountability. Institute for Political Economy, 2 Jul. 2012. Disponível em: <http:// www.paulcraigroberts.org/2012/07/02/trans-pacific-partnership-corporateescape-from-accountability/>. Acesso em: 25 jan. 2013. 
ROSSINI, C.; SUTTON, M. Don't Let them Trade A way our Internet Freedoms. Electronic Frontier Foundation, 27 Aug. 2012. Disponível em: $<$ https://www.eff.org/deeplinks/2012/08/dont-let-them-trade-away-our-internet-freedoms $>$. Acesso em: 25 jan. 2013.

TRANS-PACIFIC Strategic Economic Partnership Agreement, 2005. Disponível em: <http://www.mfat.govt.nz/downloads/trade-agreement/transpacific/ main-agreement.pdf>. Acesso em: 15 out. 2012.

WALLACH, L. NAFTA on Steroids. The Nation, 27 Jun. 2012. Disponível em: <http://www.thenation.com/article/168627/nafta-steroids $>$. Acesso em: 3 nov. 2012.

WE'RE Back. The Economist, 19 Nov. 2011. Disponível em: <http://www. economist.com/node/21538803 >. Acesso em: 15 jan. 2013.

\section{Resumo}

\section{Parceria Trans-Pacífico: Novas Geometrias no Capitalismo Global}

Em 2005, Brunei, Chile, Cingapura e Nova Zelândia firmaram acordo de parceria econômica no sentido de uma interação estratégica na região Ásia-Pacífico. Em 2009, os Estados Unidos se envolveram, assumindo a liderança das negociações. Desde então, as tratativas sobre a Parceria Trans-Pacífico ganharam impulso, com Austrália, Malásia, Peru e Vietnã aderindo em 2010 e Canadá e México em 2012, somando onze membros até o início de 2013. Baseado em pesquisa bibliográfica e documental, o artigo caracteriza essa iniciativa e discute seus termos principais e questões mais controversas. Entre estas, figuram as propostas sobre direitos de propriedade intelectual e investimentos, com vantagens para grandes empresas, inclusive na resolução de disputas entre investidores e Estados, fontes de apreensão e fortes críticas entre grupos sociais. Também se explora a motivação dos Estados Unidos, envolvendo garantia de proeminência na região de maior crescimento econômico no planeta. "Conter" a influência e a liderança chinesas parece uma estratégia central daquele país, questões econômicas e geopolíticas entrelaçando-se fortemente nesse contexto.

Palavras-chave: Economia Política Internacional - Parceria Estratégica Região Ásia-Pacífico - Geopolítica 


\section{Abstract}

\section{Trans-Pacific Partnership: New Geometries in Global Capitalism}

In 2005, Brunei, Chile, New Zealand and Singapore signed an economic partnership agreement in order to interact strategically in the Asia-Pacific region. In 2009 the United States entered the initiative and took the leadership in the negotiation. Since then the actions concerning the Trans-Pacific Partnership have gained vigor, Australia, Malaysia, Peru and Vietnam joining in 2010 and Canada and Mexico doing the same in 2012, totaling eleven members up to the beginning of 2013. Based on bibliographic and documentary research, the article presents this initiative and discusses its main terms and most controversial questions. Among the latter are the proposals on intellectual property rights and on investments, meaning benefits to big companies including on the investors-State disputes, sources of apprehension and strong criticism among social groups. The motivation of the United States, seeking prominence in the region with the highest rates of economic growth in the whole world, is also looked upon. "Containing" Chinese influence and leadership seems a central strategy of that country, questions of economic and geopolitical nature looking strongly intertwined in such a setting.

Keywords: International Political Economy - Strategic Partnership Asia-Pacific Region - Geopolitics 